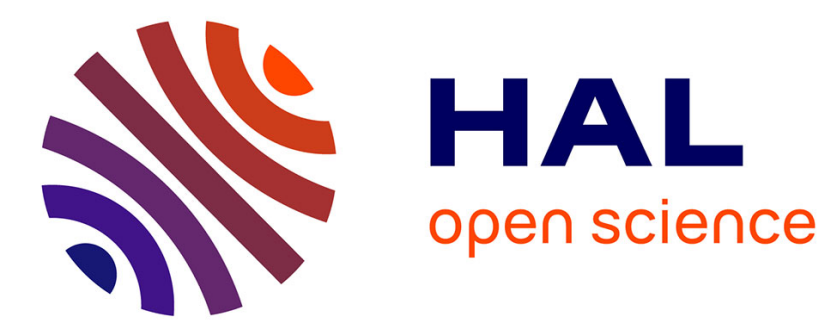

\title{
Luminescence of Aluminoborosilicate Glasses Doped with Gd3+ Ions
}

Evguenia Malchukova, A. J. Nepomnyashchikh, Bruno Boizot, T. S. Shamirzaev, Guillaume Petite

\section{- To cite this version:}

Evguenia Malchukova, A. J. Nepomnyashchikh, Bruno Boizot, T. S. Shamirzaev, Guillaume Petite. Luminescence of Aluminoborosilicate Glasses Doped with Gd3+ Ions. Physics of the Solid State, 2010, 52 (9), pp.1919. 10.1134/S1063783410090222 . hal-00512603

\section{HAL Id: hal-00512603 \\ https://hal-polytechnique.archives-ouvertes.fr/hal-00512603}

Submitted on 31 Aug 2010

HAL is a multi-disciplinary open access archive for the deposit and dissemination of scientific research documents, whether they are published or not. The documents may come from teaching and research institutions in France or abroad, or from public or private research centers.
L'archive ouverte pluridisciplinaire HAL, est destinée au dépôt et à la diffusion de documents scientifiques de niveau recherche, publiés ou non, émanant des établissements d'enseignement et de recherche français ou étrangers, des laboratoires publics ou privés. 


\title{
Luminescence of Aluminoborosilicate Glasses Doped with $\mathbf{G d}^{3+}$ Ions
}

\author{
E. V. Mal'chukovaa, ${ }^{\mathrm{a}, \mathrm{c}}$, A. I. Nepomnyashchikh ${ }^{\mathrm{b}}$, B. Boizot ${ }^{\mathrm{c}}$, T. S. Shamirzaev ${ }^{\mathrm{d},}$, , and \\ G. Petite ${ }^{\mathrm{C}}$ \\ alrkutsk State University, ul. Karla Marksa 1, Irkutsk, 664003 Russia \\ ${ }^{b}$ Vinogradov Institute of Geochemistry, Siberian Branch, Russian Academy of Sciences, ul. Favorskogo \\ 1a, Irkutsk, 664033 Russia \\ ${ }^{c}$ Laboratoire des Solides Irradiés, Ecole Polytechnique, Palaiseau Cedex, 91128 France \\ ${ }^{d}$ Institute of Semiconductor Physics, Siberian Branch, Russian Academy of Sciences, pr. Akademika \\ Lavrent'eva 13, Novosibirsk, 630090 Russia \\ *e_mail: timur@thermo.isp.nsc.ru
}

\begin{abstract}
The two photon absorption that leads to the ultraviolet upconversion luminescence in the $\mathrm{SiO}_{2}-\mathrm{Al}_{2} \mathrm{O}_{3}-\mathrm{B}_{2} \mathrm{O}_{3}-\mathrm{Na}_{2} \mathrm{O}_{3}-\mathrm{ZrO}_{2}$ : Gd ${ }^{3+}$ glass has been investigated. The inference has been made that no photon cascade emission takes place under excitation by monochromatic light corresponding to the maximum of the absorption band of the Cd3+ ion (204 nm). The mechanisms of concentration quenching and energy transfer between $\mathrm{Gd} 3+$ ions and optically active defects of the aluminoborosilicate glass have been discussed.
\end{abstract}

\section{INTRODUCTION}

Optical properties of luminescent materials prepared by doping with rare_earth (RE) ions have been widely used for generating upconversion emission in short wavelength lasers and photon cascade emission, which makes it possible to reach a quantum efficiency of luminophor above $100 \%$ [1]. The efficiency both of upconversion emission and photon cascade emission is determined by the intensity of emission of a RE ion and can be increased by transferring the energy from another type of RE ion, i.e., by doping the matrix with two types of RE ions with different structures of the energy states and the presence of active energy transfer between them. For example, $\mathrm{Tb}^{3+}$ and $\mathrm{Yb}^{3+}$ ions have been intensively studied as activators of crystalline luminophors converting infrared and visible radiation to ultraviolet radiation [2-4]. The LiGdF4 crystals doped with $\mathrm{Tb}^{3+}$ and $\mathrm{Er}^{3+}$ have been considered two photon radiators converting one UV photon into two or more visible photons [5]. An important alternative to crystals as matrices for RE doping are glasses, whose advantages are a low cost of synthesis, the possibility of introducing 
a large number of RE ions, a variety of different environments of these ions, and the existence of different mechanisms of their interaction both with one another and with the matrix or its defects.

In this work, we used the photoluminescence (PL) and photoluminescence excitation methods to study the properties of aluminoborosilicate glasses doped with $\mathrm{Gd}^{3+}$ ions. The wide energy gap $\left(32000 \mathrm{~cm}^{-1}\right)$ between the ground $\left({ }^{8} S_{7 / 2}\right)$ and the first excited $\left({ }^{6} P_{7 / 2}\right)$ states of a $\mathrm{Gd}^{3+}$ ion [6-8] allows one to treat this ion as a hypothetical mediator (sensitizer) between the matrix and other RE ions. Other possible mechanisms of energy transfer between $\mathrm{Gd}^{3+}$ ions and optically active defects of the aluminosilicate matrix are discussed.

\section{SAMPLES AND EXPERIMENTAL TECHNIQUE}

The synthesis of the aluminoborosilicate glass used as a matrix was thoroughly described in $[9,10]$. In the present work, we employed undoped aluminoborosilicate glasses or glassed doped with $0.18,0.38,0.54$, and $0.88 \mathrm{~mol} \% \mathrm{Gd}$. The photoluminescence and photoluminescence excitation spectra of the aluminoborosilicate glasses doped with $\mathrm{Gd}^{3+}$ were recorded on a Hitachi_2500 spectrophotometer. The luminescence spectra were also measured using a Spectra Physics INDI setup with pulsed excitation by a Nd: YAG laser. The laser radiation passing through a sample was recorded by an ANDOR TRIAX spectrometer (grating, $150 \mathrm{~mm}^{-1}$ ) combined with an ANDOR Istar Intensified CCD camera.

\section{EXPERIMENTAL RESULTS}

Figure 1a shows the photoluminescence spectra of the aluminoborosilicate glass doped with $\mathrm{Gd}^{3+}$ under excitation by light with different wavelengths. In all spectra, the $312 \mathrm{~nm}$ band corresponding to the ${ }^{6} P_{7 / 2}-{ }^{8} S_{7 / 2}$ optical transition of the $\mathrm{Gd}^{3+}$ ion is observed regardless of the excitation energy. For comparison, Fig. $1 \mathrm{~b}$ shows the photoluminescence spectra of the undoped aluminoborosilicate glass under excitation by monochromatic light with $\lambda=204 \mathrm{~nm}$ and under laser excitation with $\lambda=355 \mathrm{~nm}$. The photoluminescence spectrum in the range of $312 \mathrm{~nm}$ consists of three overlapping 
bands $(307,312$, and $323 \mathrm{~nm}$ ) (see inset to Fig. 1a), which were identified in [11, 12] with emission of $\mathrm{Gd}^{3+}$ ions in three different crystallographic positions. The emission associated with the transitions in optically active defects in the glass structure is observed in the spectral range 450-600 nm [13, 14]. Indeed, as can be seen from Fig. 2, the photoluminescence excitation spectra with recording of emission at the frequencies assigned to these defects do not correspond to any transition associated with the absorption in the $\mathrm{Gd}^{3+}$ ion (Fig. 3, curve 2). Figure 3 shows the photoluminescence excitation spectrum of the $312 \mathrm{~nm}$ band and the absorption spectrum. In the photoluminescence excitation spectrum, we can see three typical groups of bands that can be associated with the transitions from the ground state of the $\mathrm{Gd}^{3+}$ ion to higher excited states: ${ }^{8} S_{7 / 2}-{ }^{6} P_{7 / 2},{ }^{6} / J$, and ${ }^{6} D_{J}[15-19]$.

It should be noted that laser excitation $(\lambda=355 \mathrm{~nm}(3.49 \mathrm{eV}))$ of the aluminoborosilicate glass doped with $\mathrm{Gd}^{3+}$ leads to the appearance of upconversion luminescence with a shorter wavelength of $312 \mathrm{~nm}(3.97 \mathrm{eV})$, i.e., with a quantum energy higher than the energy of the exciting radiation. This fact can indicate the occurrence of two photon absorption in the $\mathrm{Gd}^{3+}$ ion. Actually, the study of the luminescence intensity as a function of the laser excitation intensity confirms the occurrence of the two photon process (Fig. 4).

Figure 5 shows the ratio between the intensities of photoluminescence bands of $\mathrm{Gd}^{3+}$ (312 nm) and optically active defects (450-600 nm) for different gadolinium concentrations in glass. As can be seen from the figure, the dependence is a decreasing function of the $\mathrm{Gd}^{3+}$ ion concentration. The explanation of the dependence obtained is given below.

\section{ANALYSIS OF THE DATA OBTAINED}

The $\mathrm{Gd}^{3+}$ ion has a $4 f 7$ electron configuration and the energy band $\left(\sim 32000 \mathrm{~cm}^{-1}\right)$ between the ground singlet $\left({ }^{8} S_{7 / 2}\right)$ and first excited $\left({ }^{6} P_{7 / 2}\right)$ electronic states. It was theoretically demonstrated [20] that the $4 f 7$ electron levels of gadolinium extend up to $150000 \mathrm{~cm}^{-1}$, but only the states extending up to $67000 \mathrm{~cm}^{-1}$ were revealed experimentally [15]. Since the glass matrix strongly absorbs in the UV range, thus 
hindering the luminescence of $\mathrm{Gd}^{3+}$ from the upper excited levels, the optical properties of the $\mathrm{Gd}^{3+}$ ion in glasses have not been adequately investigated [21-24]. Actually, as follows from the analysis of the photoluminescence excitation spectra for the $312 \mathrm{~nm}$ band and the absorption spectra of the aluminoborosilicate glass doped with $\mathrm{Gd}^{3+}$ ions (Fig. 3), the transitions to higher excited states (namely, the ${ }^{8} S_{7 / 2}-{ }^{6} G_{J}$ transitions, which correspond to the absorption in the range of $204 \mathrm{~nm}$ [15]) are absent, which can be caused by the opacity of the aluminoborosilicate matrix for photons with an energy above $5 \mathrm{eV}$. The absorption spectrum of the glass doped with $\mathrm{Gd}^{3+}$ ions (Fig. 3) consists of bands corresponding to the $f-f$ transitions in the $\mathrm{Gd}^{3+}$ ion and a wide band assigned to the absorption by the matrix or defects of this matrix $[13,14]$. Therefore, the band gap (the gap between the valence and conduction bands) for the aluminoborosilicate glass doped with $\mathrm{Gd}^{3+}$ ions can be roughly evaluated by $5.2 \mathrm{eV}$. The value obtained corresponds to the edge of the absorption band of an oxide glass (5.21 eV) having the composition $20 \mathrm{La}_{2} \mathrm{O}_{3}-22 \mathrm{Al}_{2} \mathrm{O}_{3}-23 \mathrm{~B}_{2} \mathrm{O}_{3}-35\left(\mathrm{SiO}_{2}+\mathrm{GeO}_{2}\right)$ where lanthanum is partially replaced by gadolinium [25].

In the photoluminescence spectra under excitation by light with $\lambda=204 \mathrm{~nm}(6.08 \mathrm{eV})$ and in the case of two photon absorption at $\lambda=355 \mathrm{~nm}(3.49 \mathrm{eV})$, there are the 312 $\mathrm{nm}$ band $(3.97 \mathrm{eV})$ corresponding to the transition from the first excited state ${ }^{6} P_{7 / 2}$ of the $\mathrm{Gd}^{3+}$ ion to the ground state ${ }^{8} S_{7 / 2}$ (Fig. 1a) $[15,16]$ and emission in the range 450-600 $\mathrm{nm}$, which is assigned to the aluminoborosilicate matrix or defects of this matrix. This luminescence is also typical of the undoped aluminoborosilicate glass (Fig. 1b). Moreover, it was revealed that the shape of the wide emission band of these defects is independent of the nature of the RE impurity (samarium or ytterbium) and only fluctuations of the maximum of the emission band as a function of the dopant are possible. The photoluminescence lines lying in the range 450-600 nm can be assigned neither to the presence of gadolinium in the aluminoborosilicate matrix nor to possible contaminating impurities of other RE elements, because, as we can see from Fig. 2, the photoluminescence excitation spectra of these lines in the wavelength range 200-280 $\mathrm{nm}$ differ from the photoluminescence excitation spectra of other RE elements. Moreover, the photoluminescence excitation spectra at a wavelength of $608 \mathrm{~nm}$ for the aluminoborosilicate glass doped with $\mathrm{Gd}^{3+}$ ions, which is usually assigned to photon 
cascade emission with the participation of $\mathrm{Gd}^{3+}$ ions in wide band gap crystals $[15,16$, 18] (for example, in oxyfluoroborate glass, it is observed with a maximum at approximately $601 \mathrm{~nm}$ [23]), also have no features typical of $\mathrm{Gd}^{3+}$ (Figs. 2, 3).

However, it should be taken into account that an important condition providing effective photon cascade emission in a sample is the absorption by the matrix and the energy transfer to the ${ }^{6} G_{J}$ states [26]. As was shown above, the aluminoborosilicate glass under is opaque to light with a quantum energy above $5.2 \mathrm{eV}$. However, the presence of the $204 \mathrm{~nm}$ band in the photoluminescence excitation spectra of the aluminoborosilicate glass doped with $\mathrm{Gd}^{3+}$ ions indicates the presence of the band-band transition assigned to the excitation of the matrix itself. In the absence of the gadolinium impurity, the energy of excitation of the matrix is transferred to optically active defects (emission in the range 450-600 nm), and, in the case of doping with gadolinium, the energy of the matrix migrates to the ${ }^{6} D_{J}$ levels of the $\mathrm{Gd}^{3+}$ ion with subsequent non radiative relaxation to the ${ }^{6} P_{7 / 2}$ level and luminescence at $312 \mathrm{~nm}$. The energy transfer from the ${ }^{6} D_{J}\left(\right.$ or ${ }^{6} P_{J}$ ) levels of the $\mathrm{Gd}^{3+}$ ion to the levels of defects with subsequent emission is also possible. Both processes can take place in the aluminoborosilicate glass doped with Gd3+ ions: under irradiation by light of a Xe lamp $(\lambda=204 \mathrm{~nm})$, the luminescence of gadolinium at $312 \mathrm{~nm}$ is excited more intensively, even though with a lower intensity than in the case where the luminescence is excited by light with the frequencies of the intraconfiguration $f-f$ transitions of $\mathrm{Gd}^{3+}$; this is accompanied by the recording of luminescence of defects.

The proposed hypothesis regarding the migration of the energy in the aluminoborosilicate glass doped with $\mathrm{Gd}^{3+}$ ions is confirmed by the results of the experiments on laser excitation by light with $\lambda=355 \mathrm{~nm}$. As can be seen from Fig. 5 , the intensity of luminescence of defects and $\mathrm{Gd}^{3+}$ ions upon the ${ }^{6} P_{7 / 2}-{ }^{8} S_{7 / 2}$ transition depends on the concentration. From the analysis of the ratio between the intensities of luminescence bands of gadolinium, we can make the inference that, first, with an increase in the doping level, nonradiative energy transfer between closely spaced gadolinium ions is possible, which leads to concentration quenching of gadolinium luminescence $[23,27]$. Second, the factor responsible for the decrease in the intensity of the 312_nm luminescence band can be the interaction between a gadolinium ion and a 
defect, which is accompanied by energy transfer to this defect and, as a result, an increase in the intensity of emission of the defect.

It was reliably established [14, 28-30] that photosensitivity of a luminophor is associated with the photo induced transformation of previously existing point defects in the glass matrix or with the formation of new defects. A special role is played by specific defects associated with partially reduced $\mathrm{Si}$ or Ge varieties in silicate or germanate glasses: the so called oxygen deficient centers [14]. Structural models of oxygen deficient centers involving $\mathrm{Si}$ or $\mathrm{Ge}$ are debatable and contradictory predominantly because of the diamagnetic nature of these defects and, as a rule, impossibility of identifying them with the use of EPR. In our studies, we used the multicomponent glass (five different oxides), so we cannot identify the observed luminescence $(450-600 \mathrm{~nm})$ with silicon-oxygen deficient defects. However, it seems reasonable to use the data of spectroscopic analysis for centers associated with $\mathrm{Si}$ as a model system for explaining the processes taking place in unirradiated aluminoborosilicate glass doped with $\mathrm{Gd}^{3+}$ ions. The behavior of paramagnetic defects in irradiated undoped [31, 32] and $\mathrm{RE}^{3+}$ doped $[9,10]$ aluminoborosilicate glasses has been studied in sufficient detail. Moreover, an increase in the efficiency of luminescence of undoped sol-gel $\mathrm{SiO}_{2}$ can be found in its doping by $\mathrm{Ni}^{+}$or $\mathrm{Mn}^{2+}$ ions [26]. Therefore, the energy transfer in the aluminoborosilicate glass doped with $\mathrm{Gd} 3+$ ions can be schematically represented as follows (Fig. 6). Under the $f-$ $f$ excitation, in the $\mathrm{Gd}^{3+}$ ion $(245,275 \mathrm{~nm})$, there appear excitations of the ${ }^{6} D_{J}$ and ${ }^{6} / J$ levels, respectively. After multiphoton relaxation to the ${ }^{6} P_{7 / 2}$ level, there occurs intensive emission to the ground level ${ }^{8} S_{7 / 2}$ of the $\mathrm{Gd}^{3+}$ ion. In this case, the emission by defects either is not recorded or is insignificant.

Another situation takes place under excitation at $\lambda=204 \mathrm{~nm}$, which corresponds to the band-band transition in the aluminoborosilicate matrix. In view of the overlapping of the excited states of the matrix and the ${ }^{6} D_{J}$ states of the $\mathrm{Gd}^{3+}$ ion, the energy of excitation of the aluminoborosilicate matrix is effectively transferred to the gadolinium ion. The matrix ${ }^{6} D_{J}$ state interaction is confirmed by the observed UV luminescence $(312 \mathrm{~nm})$ and the absence of photon cascade emission from the energy levels of $\mathrm{Gd}^{3+}$ higher than ${ }^{6} \mathrm{G}_{J}$. The same scheme occurs in the case of two photon absorption $(\lambda=355 \mathrm{~nm})$. After transferring the energy of excitation of the matrix to the gadolinium ion, upconversion 
luminescence $(312 \mathrm{~nm})$ is observed. In both cases, the migration of energy proceeds between $\mathrm{Gd}^{3+}$ ions and optically active defects, i.e., oxygen deficient centers, which can be associated not only with the Si ions [13] but, due to multicomponent character of the matrix under investigation, with other glass formers responsible for the formation of the aluminoborosilicate glass network.

\section{CONCLUSIONS}

By using the results obtained, we have constructed the energy scheme and the model of energy transfer in the aluminoborosilicate glass doped with $\mathrm{Gd}^{3+}$ ions under laser excitation and excitation by monochromatic light of the Xe lamp. It has been shown that, under laser excitation $(\lambda=355 \mathrm{~nm})$, the $312 \mathrm{~nm}$ emission results from two_photon absorption and represents upconversion luminescence. In both cases, photon cascade emission of $\mathrm{Gd}^{3+}$ ions in the aluminoborosilicate glass has not been revealed, which can be explained by the opacity of the glass under investigation in the UV range (the band gap is approximately equal to $5.2 \mathrm{eV}$ ). The luminescence observed under excitation at the wavelengths $\lambda=204$ and $355 \mathrm{~nm}$ in the range $450-600 \mathrm{~nm}$ is associated with the oxygen deficient defects in the glass. The analysis of spectroscopic data has demonstrated that, with an increase in the concentration of gadolinium, the intensity of luminescence of $\mathrm{Gd}^{3+}$ ions decreases (concentration quenching takes place) and the efficiency of luminescence of optically active defects increases as a result of the energy transfer between gadolinium ions and these defects.

\section{REFERENCES}

1. A. S. Potapov, P. A. Rodnyi, S. B. Mikhrin, and I. R. Magunov, Fiz. Tverd. Tela (St. Petersburg) 47 (8), 1386 (2005) [Phys. Solid State 47 (8), 1436 (2005).

2. F. Auzel, Chem. Rev. 104, 139 (2004).

3. F. W. Ostermayer and L. G. Van Uitert, Phys. Rev. B: Solid State 1, 4208 (1970).

4. M. A. Noginov, P. Venkateswarlu, and M. Mahadi, J. Opt. Soc. Am. B 13, 735 (1996).

5. R. T. Wegh, E. V. D. van Loef, and A. Meijerink, J. Lumin. 90, 111 (2000). 
6. G. H. Dieke, Spectra and Energy Levels of Rare Earth lons in Crystals (Interscience, New York, 1968).

7. W. T. Carnall, G. L. Goodman, K. Rajnak, and R. S. Rana, Argonne Natl. Lab. [Tech. Rep.], No. ANL_88_8 (1988).

8. H. Kondo, T. Hirai, and S. Hashimoto, J. Lumin. 102, 727 (2003).

9. E. Malchukova, B. Boizot, D. Ghaleb, and G. Petite, J. Non_Cryst. Solids 352, 297 (2006).

10. E. Malchukova, B. Boizot, G. Petite, and D. Ghaleb, J. Non_Cryst. Solids 353, 2397 (2007).

11. Z. Yang, J. H. Lin, M. Z. Su, Y. Tao, and W. Wang, J. Alloys Compd. 308, 94 (2000).

12. D. Di Martino, A. Krasnikov, M. Nikl, K. Nitsch, A. Vedda, and S. Zazubovich, Phys. Status Solidi A 201, R38 (2004).

13. Z. Tian, H. Liang, B. Han, Q. Su, Y. Tao, G. Zhang, and Y. Fu, J. Phys. Chem. C 112, 12524 (2008).

14. L. Skuja, J. Non_Cryst. Solids 239, 16 (1998).

15. R. T. Wegh, H. Donker, A. Meijerink, R. L. Lamminmaki, and J. Holsa, Phys. Rev. B: Condens. Matter 56, 13841 (1997).

16. P. J. Deren, W. Strek, and J._C. Krupa, Chem. Phys. Lett. 928, 217 (1998).

17. A. J. Vries, M. F. de Hazekamp, and G. Blasse, J. Lumin. 42, 275 (1988).

18. P. J. Alonso, V. M. Orera, R. Cases, R. Alcala, and V. D. Rodriguez, J. Lumin. 39, 275 (1988).

19. R. Reisfeld, E. Greenberg, R. Velapoldi, and B. Barnett, J. Chem. Phys. 56, 1698 (1972).

20. G. H. Dieke and H. M. Crosswhite, Appl. Opt. 2, 675 (1963).

21. J. W. V. Verwey, G. F. Imbusch, and G. Blasse, J. Phys. Chem. Solids 50, 813 (1989).

22. K. Binnemans, R. Van Deun, C. Goerller_Walrand, and J. L. Adam, J. Non_Cryst. Solids 238, 11 (1998).

23. A. Kumar, D. K. Rai, and S. B. Rai, Solid State Commun. 117, 387 (2001).

24. A. Kumar, D. K. Rai, and S. B. Rai, Spectrochim. Acta, Part A 57, 2587 (2001). 
25. J. Kliava, A. Malakhovskii, I. Edelman, A. Potseluyko, E. Patrakovskaja, S. Melnikova, T. Zarubina, G. Petrovskii, Y. Bruckental, and Y. Yeshurun, Phys. Rev. B: Condens. Matter 71, 104406 (2005).

26. P. Yang, C. F. Song, M. K. Lu, J. Chang, Y. Z. Wang, Z. X. Yang, G. J. Zhou, Z. P. Ai, D. Xu, and D. L. Yuan, J. Solid State Chem. 160, 272 (2001).

27. L. Brixner, M. Crawford, J._L. Adam, and J. Lucas, C. R. Acad. Sci., Ser. II: Mec., Phys., Chim., Sci. Terre Univers 309, 1541 (1989).

28. S. Agnello, R. Boscaino, F. La Mattina, S. Grandi, and A. Magistris, in Proceedings of the 2005 IEEE/LEOS Workshop, Eindhoven, The Netherlands, 2005, p. 422.

29. A. H. Edwards, in Defects in Glasses, Ed. By F. L. Galeener, D. L. Griscom, and M. J. Weber (Materials Research Society, Pittsburgh, PA, United States, 1986), p. 3.

30. T. Uchino, M. Takahashi, and T. Yoko, Phys. Rev. Lett. 86, 1777 (2001).

31. B. Boizot, G. Petite, D. Ghaleb, and G. Calas, Nucl. Instum. Methods Phys. Res., Sect. B 141, 580 (1998).

32. B. Boizot, G. Petite, D. Ghaleb, and G. Calas, J. Non_Cryst. Solids 283, 179 (2001). 

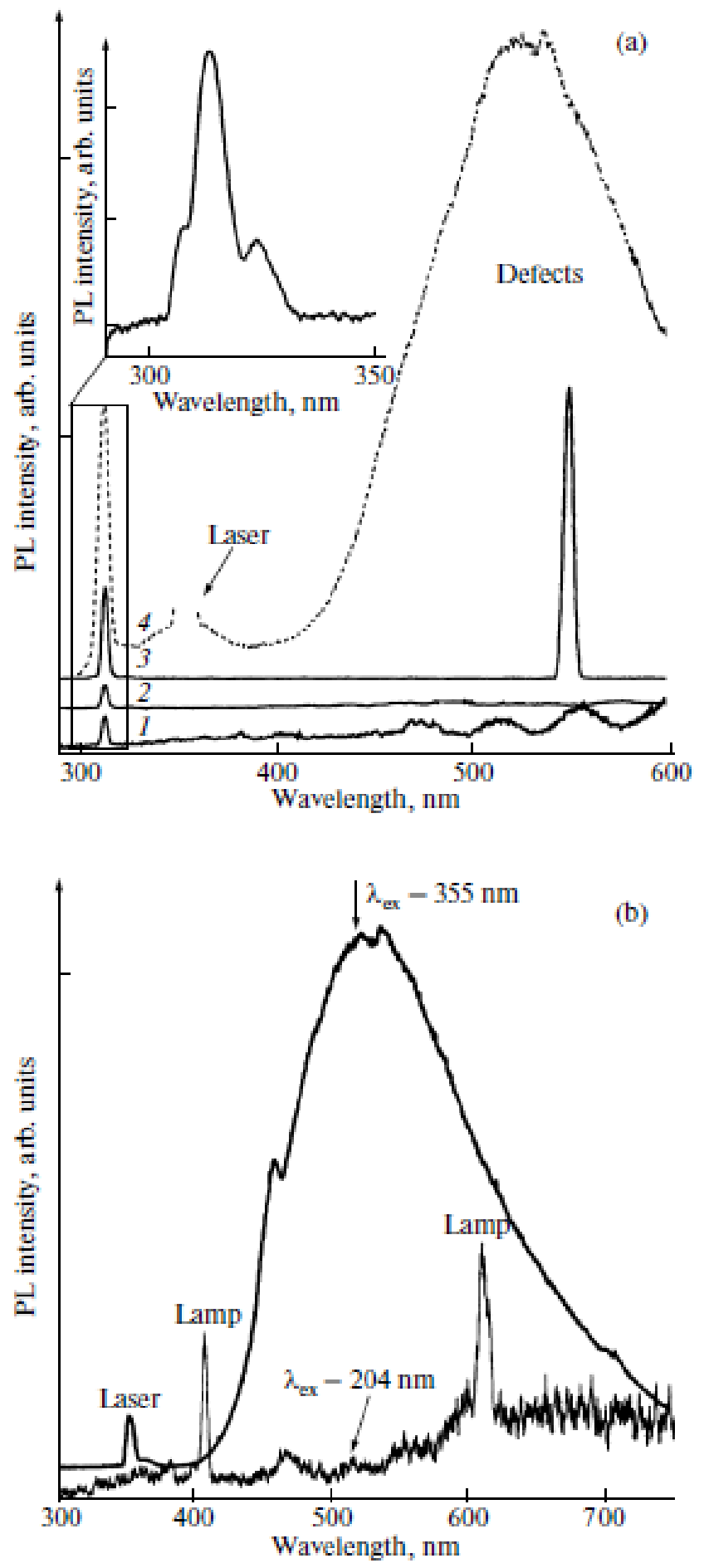

Fig. 1. Photoluminescence spectra under excitation by light with different wavelengths $\lambda_{e x}$ : (a) aluminoborosilicate glass doped with $\mathrm{Gd}^{3+}$ ions $(0.88 \mathrm{~mol} \%)$ and (b) undoped aluminoborosilicate glass, $\lambda_{\mathrm{er}}=(I) 204 \mathrm{~nm}$ (Xe lamp), (2) $245 \mathrm{~nm}$ (Xe lamp), (3) $275 \mathrm{~nm}$ (Xe lamp), and (4) $355 \mathrm{~nm}$ (Nd: YAG laser). The inset shows the spectral portion corresponding to the ${ }^{6} P_{7 / 2}-{ }^{8} S_{7 / 2}$ optical transition of the $\mathrm{Gd}^{3+}$ ion. 


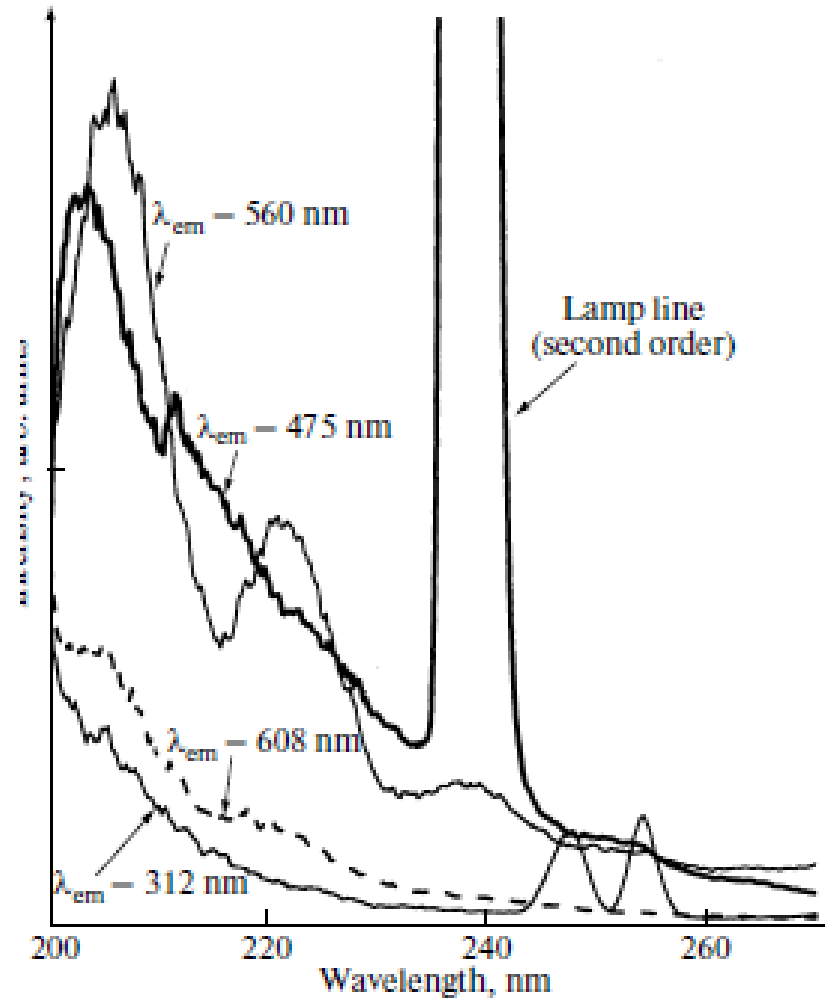

Fig. 2. Photoluminescence excitation spectra of the aluminoborosilicate glass doped with $\mathrm{Gd}^{3+}$ ions $(0.88 \mathrm{~mol} \%)$ in the range of emission of defects at the wavelengths $\lambda_{\mathrm{em}}=$ 475,560 , and $608 \mathrm{~nm}$. For comparison, the photoluminescence excitation spectrum of the band of $\mathrm{Gd}^{3+} \lambda_{\mathrm{em}}=312 \mathrm{~nm}$ for the same sample is shown. 


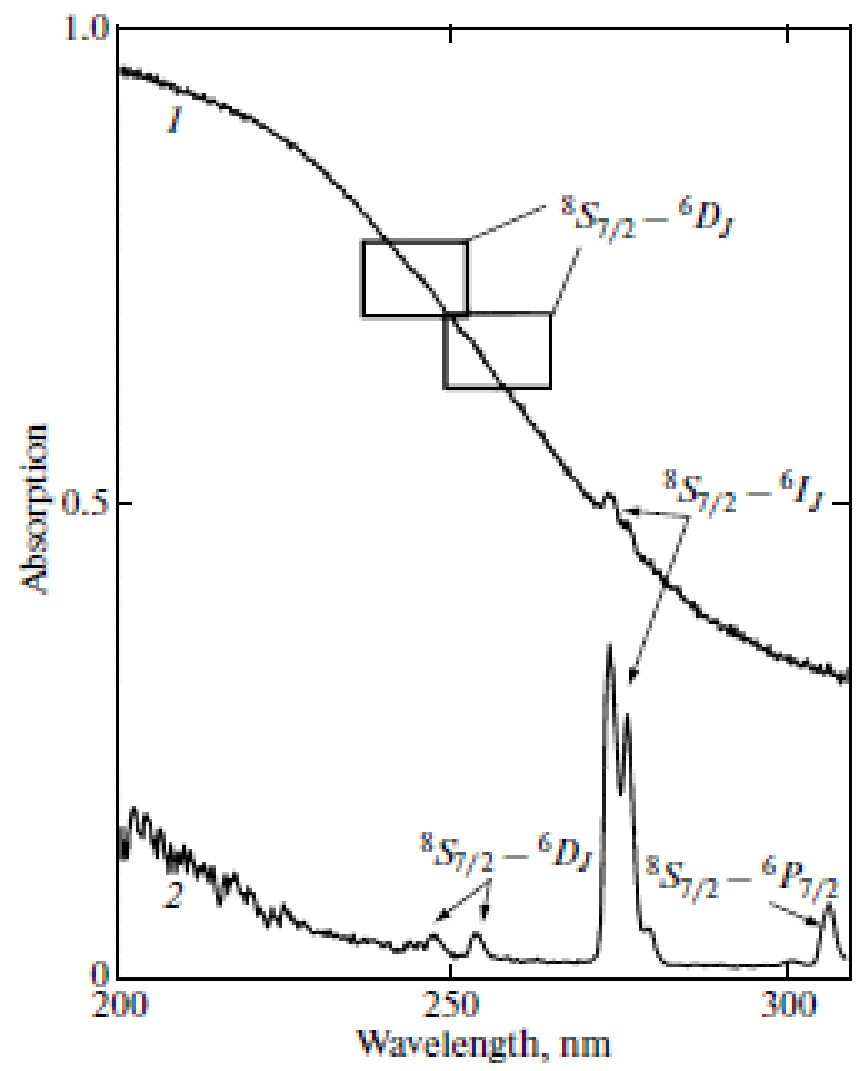

Fig. 3. (1) Absorption and (2) photoluminescence excitation spectra of the 312-nm band of the aluminoborosilicate glass doped with $\mathrm{Gd}^{3+}$ ions $(0.88 \mathrm{~mol} \%)$ at room temperature. 


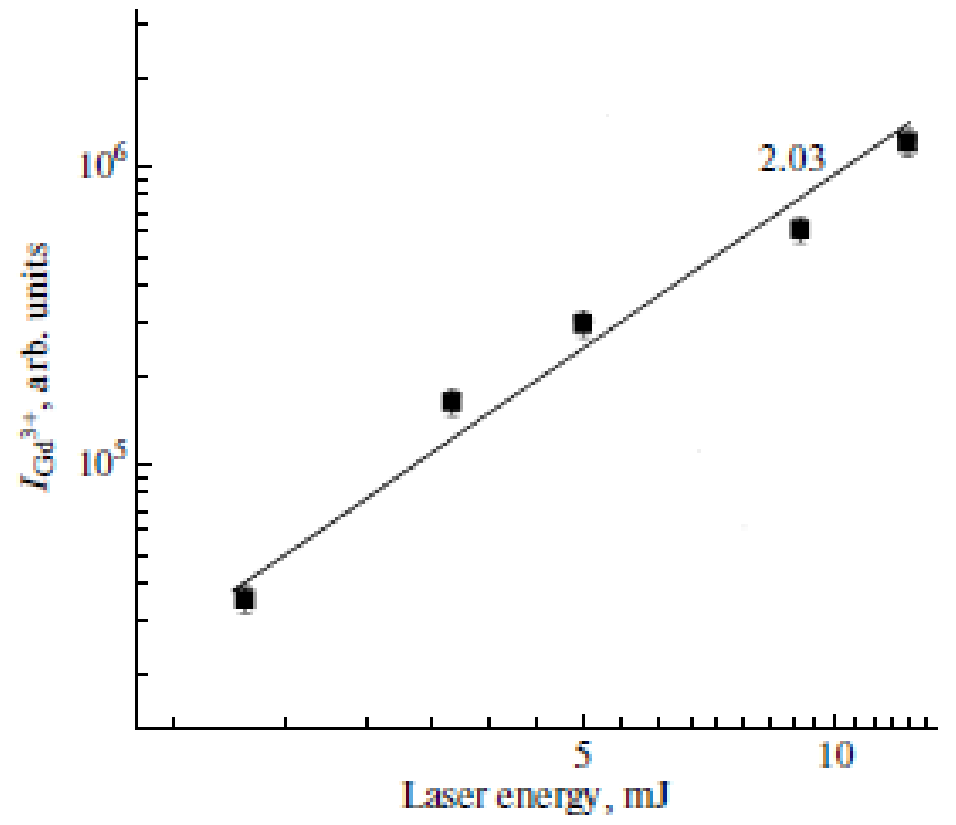

Fig. 4. Dependence of the intensity of the luminescence band at $312 \mathrm{~nm} I_{\mathrm{Gd}^{3}}$, on the intensity of exciting light with $\lambda_{\mathrm{ex}}=355 \mathrm{~nm}$. The number in the graph indicates the slope of the straight line on a double logarithmic scale. 


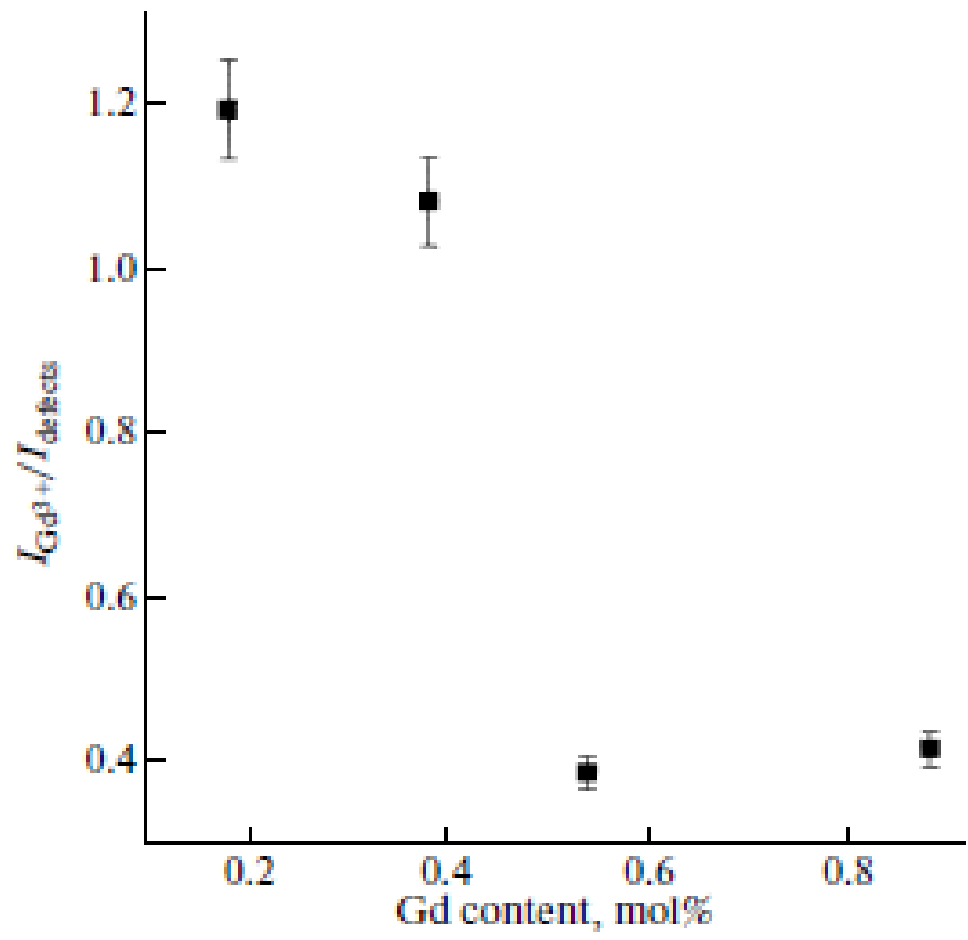

Fig. 5. Relationship between the intensities of the luminescence bands of $\mathrm{Gd}^{3+}$ ions and optically active defects of the aluminoborosilicate glass for different gadolinium concentrations ( $\lambda_{\mathrm{ex}}=355 \mathrm{~nm}$, Nd : YAG laser). 


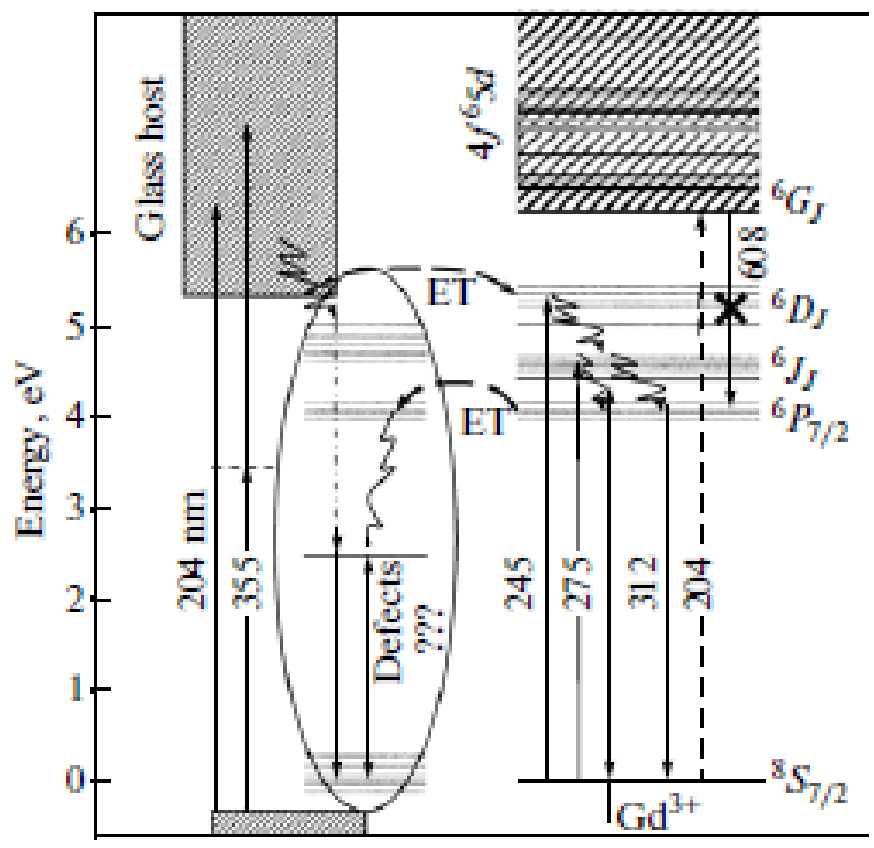

Fig. 6. Scheme of the levels of a $\mathrm{Gd}^{3+}$ ion and a model describing the mechanisms of energy transfer (ET) and origin of the luminescence in the aluminoborosilicate glass doped with $\mathrm{Gd}^{3+}$ ions. The transition shown by the thick dashed arrow corresponds to band-band absorption of the aluminoborosilicate matrix, and the transition marked by the cross is not observed in the glass under investigation. 